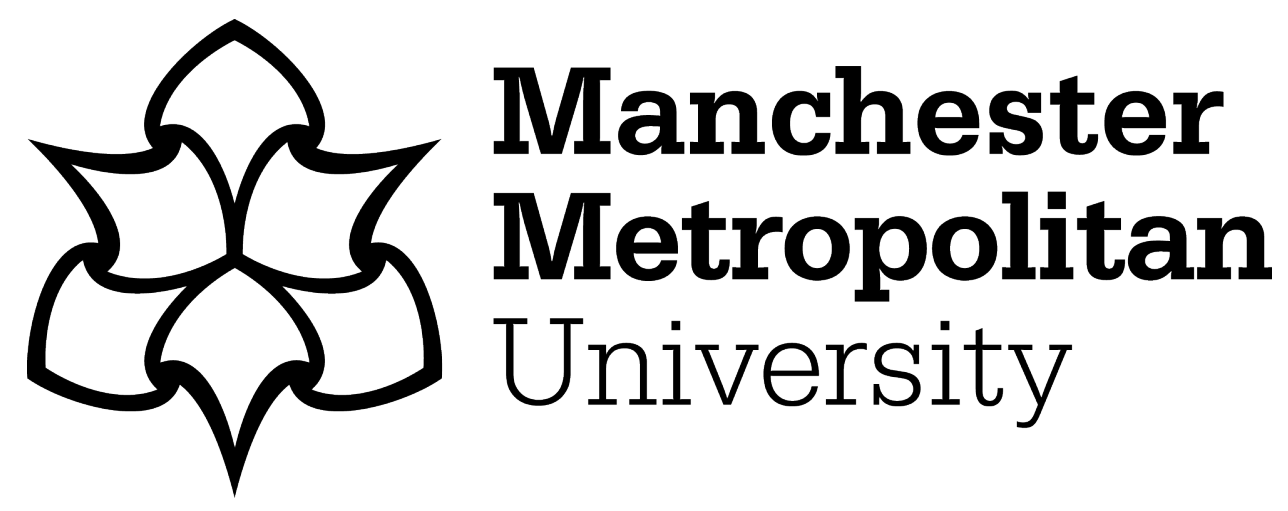

Pollock, K, Wilkinson, S ORCID logoORCID: https://orcid.org/0000-00021564-5472, Perry-Young, L, Turner, N and Schneider, J (2021) What do family care-givers want from domiciliary care for relatives living with dementia? A qualitative study. Ageing and Society, 41 (9). pp. 2060-2073. ISSN 0144$686 \mathrm{X}$

Downloaded from: https://e-space.mmu.ac.uk/628650/

Version: Accepted Version

Publisher: Cambridge University Press

DOI: https://doi.org/10.1017/S0144686X20000185

Usage rights: Creative Commons: Attribution-Noncommercial-No Derivative Works 4.0

Please cite the published version 


\title{
What do family care-givers want from domiciliary care for relatives living with dementia? A qualitative study
}

\author{
Kristian Pollock ${ }^{1 \star}$, Samantha Wilkinson ${ }^{2}$, Lucy Perry-Young ${ }^{3}$, Nicola Turner ${ }^{1}$ \\ and Justine Schneider ${ }^{1,4}$ \\ ${ }^{1}$ School of Health Sciences, University of Nottingham, Nottingham, UK, ${ }^{2}$ School of Childhood, Youth and \\ Education Studies, Manchester Metropolitan University, Manchester, UK, ${ }^{3}$ Department of Allied Health \\ Professions, Sheffield Hallam University, Sheffield, UK and ${ }^{4}$ School of Sociology and Social Policy, \\ University of Nottingham, Nottingham, UK \\ *Corresponding author. Email: kristian.pollock@nottingham.ac.uk
}

(Accepted 16 January 2020; first published online 6 March 2020)

\begin{abstract}
In the current ecology of care, social, rather than medical, support is critical in enabling frail older people to live at home. This paper reports findings from a qualitative study about how home care workers (HCWs) support persons with dementia living in the community. Semi-structured qualitative interviews were carried out in England with 14 family care-givers (FCGs) recruited from a single private home care provider. A thematic analysis of the data was undertaken using the constant comparative method. In every instance, it was FCGs who initiated domiciliary care for the person with dementia, highlighting ambiguity about who is the 'client'. Rather than focusing on the HCWs' work in undertaking practical tasks and personal care, respondents prioritised HCWs as companions, providing emotional and social support for their relatives. From an organisational perspective, respondents valued the capacity of the provider to deliver a consistent, personal, reliable and punctual service. These attributes were important in supporting their relative's agency and dignity. Respondents described HCWs engaging in skilled and sensitive communication with clients but considered 'character' and 'innate' caring abilities to be more import-ant than those derived from training. The results highlight the need to acknowledge the family, rather than the individual client, as the functioning unit of care, and to recognise the highly skilled communicative and emotional work undertaken by HCWs.
\end{abstract}

Keywords: home care; dementia; qualitative; family care-givers

\section{Introduction}

In the current ecology of care, it is the need for social rather than medical support that is often critical in enabling frail older people to continue to live at home. This paper reports qualitative findings from a study, 'Broadening Our Understanding of Good Homecare' (BOUGH), of the role of home care workers (HCWs) in 
supporting clients with dementia to remain living at home. It focuses on the experience, perspectives and priorities of family care-givers (FCGs) who organised and monitored their relatives' care. The paper contributes to an understanding of the meaning of 'home care' and how this is constructed in different perspectives within the context of a policy shift to private rather than state-funded provision. It also highlights the relational nature of care, and the significant contribution of HCWs to a network of care extending beyond the cared-for individual, to the wider family unit.

Despite the acknowledged social and economic importance of informal care provision, little consideration has been given to how meeting their relative's increasingly complex care needs impacts on family members (Wiles, 2003; Burton, 2006; Fraser et al., 2014; Manthorpe et al., 2016; Oliveira et al., 2017), or of how the appropriation of private spaces by the providers of professional and social care impacts on clients' and relatives' sense of what 'home' is (Aronson, 2002; Dyck et al., 2005; Milligan et al., 2016).

Previous studies have reported complex and ambivalent responses of FCGs to paid home care (Ohwaki et al., 2009; Adelman et al., 2014; Fraser et al., 2014). Experience of poor or inadequate care, or concerns about the need for paid care signalling a significant transition towards loss of independence, personal autonomy and privacy, may underlie such ambivalence for both family care-givers and the person with dementia (Wiles, 2003; Pot et al., 2005; Taylor and Donnelly, 2006; de Sao Jose et al., 2016).

Home is widely assumed to be the best and preferred place of care for frail older people, including those affected by dementia, and to be the least costly to the state (Schneider et al., 1993; National Institute for Health and Care Excellence, 2015; Alzheimer's Society, 2016). However, increasingly such care is sustained through active support from relatives and friends (Wiles, 2003; Bunn et al., 2016; Humphries et al., 2016; Age UK, 2017). Clients and their families are expected to draw on their own financial and social resources in meeting needs for care, as the threshold for state provision becomes progressively higher (Dyck et al., 2005; Sims-Gould and Martin-Matthews, 2008; Manthorpe et al., 2016; Daly and Westwood, 2018; Wittenberg et al., 2018). The purchase of privately funded care will become increasingly significant in future (Institute of Public Care, 2011; Humphries et al., 2016). However, we currently know little about the nature of the work carried out by HCWs in the private space of the domestic home, nor how this impacts on the family members who assume responsibility for their relatives' wellbeing (Wiles, 2003; Fraser et al., 2014; Oliveira et al., 2017).

\section{Method}

The BOUGH study explored stakeholder perspectives and experience of home care through an ethnographic investigation of a private home care provider in England. This paper presents findings from a subset of the data, comprising a series of 14 semi-structured interviews with FCGs carried out between November 2016 and March 2017. The research received approval from the UK Health Research Authority Social Care Research Ethics Committee. Pseudonyms have been assigned to individual family carers and clients. The home care service has been assigned the pseudonym 'Domiciliary Care' (DC). 


\section{Participant recruitment and consent}

Having received the organisation's agreement to support the study, local DC managers were asked to distribute a letter of invitation and an information sheet about the study to relatives and, where appropriate, the clients (persons with dementia), of all local current cases identified as being affected by dementia or cognitive impairment. A second series of invitations was sent to family members of former clients so that we could include the reflective perspectives of family members who, for one reason or another, had stopped using the service. Recipients were asked to respond directly to the researchers if they were interested in taking part in the study, following which an appointment was arranged for interview. These lasted approximately one hour and were undertaken by KP and JS in participants' homes, except for one interview, which was conducted at the university. The researchers obtained written consent from participants prior to each interview.

\section{Analysis}

Semi-structured interviews were audio recorded, transcribed and imported to NVivo 11 to facilitate a thematic analysis of the data using the constant comparative method (Braun and Clarke, 2006; Charmaz, 2006; Bazeley and Jackson, 2013). After close reading of the transcripts, sections of text were allocated to one or more relevant codes from which the occurrence and interrelationships of recurring patterns or themes were identified. Initial data coding was primarily undertaken by KP. Analysis was developed during discussion in regular team meetings during which themes from the family care-giver interview data were triangulated with findings from other data streams within the study. The coding frame evolved through teamwork and discussion throughout the study.

\section{Findings}

Interviews were completed with family carers of eight past and six current clients. The person with dementia was present during several of the interviews. Although they took part in some general conversation, according to their preference and capacity, they did not actively engage in the interview itself. Over half (eight) family carers were daughters, four were husbands, one was a son and one a wife of the person with dementia. In seven cases the person with dementia lived, or had lived, alone, with local support from adult children, except for one adult child who lived in a different town. Five people with dementia lived with their spouse who was, or had been, the primary carer. The other two had resided with their adult offspring prior to moving into residential care. The duration of paid home care ranged from six months to four years. Hours of weekly paid home care ranged from five to 28 , with half of participants receiving between five and seven hours. Several participants made intermittent use of other private services, including respite care. A few reported that they supplemented DC input with social services support, including through Direct Payments. These allow clients to arrange and pay for their own care, rather than receive services directly from a local authority. 
The following sections present findings relating to respondents' accounts of how and why they initiated home care support, their views on cost and benefits of the service, the kind of care support they sought and what they valued most about the HCWs.

\section{Triggers to obtaining private domiciliary care}

Participants described several ways in which they reached a point of recognising that home care was needed. Sometimes this followed a chance encounter with company advertisements, or recommendation from a colleague or associate. Such chance contacts could trigger recognition of a 'need' that had not been previously articulated. The decision to obtain paid help sometimes followed the occurrence of a critical incident, an accident or illness, possibly requiring hospitalisation. Alternatively, the trigger point could come after a period of incremental concern about their relative's safety following worsening dementia: increasing forgetfulness, self-neglect, poor hygiene, forgetting to eat.

The choice of provider was rarely reported to result from an extensive search for, or comparison of, available options. Several respondents made contact following the opening of a DC branch in their immediate locality. Embeddedness of the service within the community was a positive advantage, giving relatives a sense of accessibility and enabling personal contact with office staff. Several participants searched online for information about care providers and one identified the company through the internet. The presentation and ethos of DC was positively assessed and inspired confidence. In every case, it was family members who took the initiative in setting up domiciliary care. This included situations where adult children initiated and organised care for parents living together, where one partner was, and remained, the primary care-giver for their spouse with dementia. In these instances, the introduction of paid care could be viewed with ambivalence, if not outright resistance, by the care-giving spouse:

Mrs Randall's husband: The family felt that we should have them.

Interviewer: And how did you feel about that?

Mrs Randall's husband: I was a bit reluctant at first. It took a bit of getting used to.

Interviewer: Yeah. Why was that?

Mrs Randall's husband: Well, I'd been doing the work myself, and didn't want anyone else.

In such cases, there was ambiguity about who was the 'client' in relation to the provider, the person with dementia or their family members; adult children or the parent who occupied the role of primary carer? Staff from DC were at pains to include the care recipient in regular checks of care quality and discussion of care plans. However, de facto it was the person with dementia's family member who was the key contact who took on responsibility for monitoring care and communicating with the company:

Communication was good with me, because they [DC] knew about Dad's dementia, so they'd always communicate with me first, but they'd always communicate with him. So, he felt involved, even if he'd remember or not. (Evan's daughter) 
Only a couple of participants referred to completion of a Lasting Power of Attorney formally conferring responsibility for management of their relative's financial affairs to them. In practice, rather than make use of legally binding directives and allocation of responsibilities, family members operated within an informal framework of mutual interest and engagement in relation to persons affected by dementia. Relatives naturally took on the role of monitoring the service provided by DC, and intervening directly if they felt that there were any problems or shortcomings in the care provided:

I think, sometimes, they [DC] thought that I would accept people [HCWs]. And I understood their problems with that. But at the end of the day, sorry. If they're not right, then, I can't let my Dad just have anybody because we're in a bad enough situation. We don't, we don't need that making even worse. (Mr Simpson's daughter)

Strong bonds of affection and familial obligation subsumed de facto entitlement of family care-givers to intervene in the person with dementia's affairs.

\section{Key features of good home care}

Participants described a range of tasks and services provided by the HCWs. Companionship was mentioned by 12 participants, provision of meals by ten, personal care and help with activities of daily living by seven. Providing respite for the informal care-giver, taking the person with dementia out and on excursions, and monitoring or supporting medicine taking were each specified by one or two participants.

Family members emphasised the role of HCWs as companions, substituting presence in the home when they were unable to be present or to enable them to have some respite for themselves. They also valued the preparation of meals, provision of personal care, where necessary, and the support they provided the person with dementia to manage their normal activities. Routine housework was not emphasised. Indeed, family members continued to provide a substantial amount of domestic and personal care for their relative, rather than delegate these to the HCWs. Respondents valued the quality of the relationship HCWs established with the person with dementia, and the extent to which this enhanced their quality of life and enabled an enrichment of activities within and outside the home:

We didn't try and give them any extra jobs, they didn't do ironing or anything like that. It was the social side as much as anything, apart from her needs. The rest of it was, if she wants to go for a walk and you've got time to take her for a walk, do it. Doesn't matter about other things, and one of them was actually beginning to do a course in massage, I think it was, and they painted her nails and, and that, to me, was over and above. (Mrs McDonald's daughter)

Respondents also valued the security of knowing that the HCWs were visiting regularly to check on the safety and wellbeing of their relative in their absence:

And, I can, that's the most important thing, that I know that there's somebody there, and they've been to see her, when I can't, I've got other things to be doing. And the rest of the family have got other things to be doing. (Mrs Allen's son) 
Provision of meals was an important activity - both for the health and wellbeing of the person with dementia and because of the opportunity this could afford for social interaction and activity.

Respondents were positive in their assessment of the company that provided care. They valued the reliability of the service and the responsiveness and flexibility of staff when problems arose. From the relatives' perspective, the most important organisational aspects of good home care were punctuality, reliability and continuity of the care-givers:

Well, I have to say, a regular and consistent small number of carers who, you know, listen to both the relatives' requests, and then obviously try to work in the context of what the actual person they're caring for wants and how they are, on that particular day. And, I mean, obviously, well, I mean, DC are superb in terms of they always turn up when they say they're going to turn up, we don't have any incidents of them, you know, not coming or you know, just, they're very reliable, in that sense. (Mrs O'Shea's daughter)

Punctuality of HCWs enabled clients to maintain routine and structure in their day. This was considered particularly important for persons affected by cognitive impairment and dementia. It was also seen to be a means of protecting dignity and personhood, meaning that the care agenda was driven by the client and recognition of their needs, rather than being subject to the scheduling priorities of an unreliable and impersonal service. Respondents also valued the minimum one-hour period of care and the continuity of care-givers specified by the provider. In this respect, DC was compared very favourably with respondents' direct or vicarious experience of provision accessed via the public sector, such as local authoritycommissioned providers. This was invariably described in very negative terms:

And, I don't know whether we'd actually looked at anything else. We didn't ... know whether we wanted county council because they are random ... Well, they could, they normally say, for breakfast, they come between half eight and ten. Well, that wouldn't have done mum. Do you know what I mean? Because she was one, let's get up and at 'em, sort of thing ... But no, we've, we were really pleased with them [DC], it worked well for us. (Mrs Edward's daughter)

One of the advantages of paying directly for care was that respondents' concerns and complaints were acknowledged and acted on promptly. This included replacement of HCWs who did not suit. Several respondents in the study described occasions when they had requested such a change, not because of shortcomings in the standard of care provided, but simply because they felt the personality or temperament of the HCW was not suited to their relative.

\section{Key features of good HCWs}

Continuity of care was considered important in enabling the development of good relationships between clients, family members and HCWs, and respondents prioritised the HCW's ability to establish these. Respondents described HCWs manifesting considerable skill and enterprise in their interactions with persons with 
dementia, and an engagement which often went beyond the remit of the job. Few HCWs had more than basic training in dementia care but brought experience and skills from their personal lives or previous occupational experience. These were considered by respondents to be more important than training in dementia care. Interest in the client, taking the time to learn about their lives and personalities, and kindness were felt to be HCWs' most important attributes:

They have got to be naturally caring. I don't think that, to care for somebody, especially dementia, it's something you can learn. You can learn about dementia, you can learn how it affects a person, but to actually have that caring understanding nature, to be able to give that care to that person, you can't learn that, that's got to be a natural gift. (Mrs Patterson's daughter)

While explicitly prioritising the character and innate caring abilities of HCWs, respondents also described, and appreciated, the range of subtle skills and management techniques that they employed:

For example, [person with dementia] was very house-proud ... she wanted her house still to be nice, I know that, even though she couldn't think 'The bathroom needs cleaning'. But, the ones who gave her a duster and went round dusting ... and said, 'Let's dust together', that was far more therapeutic than somebody who just said, 'I can't talk, I've got to get on with the dusting'. It was that engaging of the things that have been important. (Mrs Tomlinson's daughter)

The relationship between family members and HCWs varied greatly. This was partly determined by the extent of contact facilitated by the respondents' involvement in their relatives' care and whether they were co-resident. Some relatives described very close relationships with individual HCWs, even to the extent of describing them as 'part of the family':

They seemed to sort of genuinely to love Mum, and almost treat her like their own mum, and want to do for her as much as they could. But I think it also worked that we were, you know, we got very, very fond of them, so we always gave them Christmas presents, and Easter eggs, from Mum, you know ... so it was a genuine relationship, I think, rather than just people coming in and doing a job. (Mrs McDonald's daughter)

However, proximity did not necessarily result in close contact or the development of good relationships. Two respondents, both co-resident husbands of clients, reported little knowledge or interest in the HCWs who came in daily to provide support. They viewed these individuals in instrumental terms - provided simply to undertake the tasks of care:

No, they [carers] just come in and, and they're obviously trained and they know what to do, so, and they come in and dress her and wash her and you know ... I mean, these people aren't medically trained, are they? They're more or less just helpers ... Well, I suppose they're trained to do a certain, got a certain routine 
and they come and do that, and, I suppose that's sufficient, really. (Mrs Brown's husband)

Much more commonly, however, respondents appreciated HCWs who went above and beyond the narrow remit of the job and brought in aspects of their own lives and skills to care for their relatives, e.g. bringing their dogs to visit, bringing in books or photographs, giving clients a massage or painting their nails.

\section{Benefits for relatives}

Respondents' priority in organising paid care was to promote the wellbeing, best interests and independent living of their relative. In addition, it was evident that the support provided by the HCWs could have a beneficial impact on their own lives. Respondents valued home care as a means of enabling the person with dementia to remain at home for the longest possible time:

Oh, it's brilliant. That, to me, was a godsend. It was a lifesaver, and that enabled me to, like, carry on caring for my Mum, probably a lot longer. (Mrs Patterson's daughter)

Home care enabled a delegation of time and care, and associated responsibility, and relieved part of their own responsibility for care. HCW input provided reassurance in substituting for the self when respondents were not able to be physically present in the home. Several respondents described home care as enabling themselves and family members to carry on functioning at work and as a family:

Only that I am eternally grateful for the level of care that they gave to Mum, because ... it enabled us to carry on family life. (Mrs Tomlinson's daughter)

Home care provided an opportunity for relatives to take time out for themselves, even if this was only to find some personal space within the house. In an important sense, the HCWs provided support and care for the family, as well as for the person with dementia. Several participants described strong and appreciative bonds with HCWs. For instance, one spouse described how he had formalised a division of labour for the HCW's visits, so that part of the time was reserved for the two of them to enjoy tea and conversation:

I said to the person, the carers we had, she'd come for ... an hour, and threequarters of that is looking after [person with dementia/wife] and quarter of an hour is respite with me. Because we sit in here, when she's finished, we come in here, I've got the tea ready and all the rest, the cup of tea and the biscuits and what have you. And that quarter of an hour is absolute respite of the first order to me. (Mrs Thomson's husband)

For Mr Thomson, the carer's visit provided welcome respite from the many hours during the rest of the day when he was confined to the house and the uncommunicative company of his wife who was affected by severe dementia. 


\section{The costs of care}

Privately provided home care is expensive, and most respondents were clearly fortunate in terms of the resources they could access to pay for care, especially as need and hours of care increased. We did not ask for detailed information about costs and sources of payment, but respondents referred to all or most of the charges being drawn from the person with dementia's estate, often through capital tied up in property, or a pension. A couple of relatives described receiving some contribution through state benefits and Direct Payments. The cost of care was accepted as necessary - the going rate for the job - and considered essential to the wellbeing of the person with dementia and the wider family. Several respondents considered the service they obtained to represent 'good value for money' and that 'you get what you pay for':

Oh ... The cost ... I thought the cost was fine. Which sounds very glib. But you know, got up to about ... $£ 18$ or $£ 19$ an hour: you've got admin costs, you've got setting up your business costs, you've got people that have got to live on, you've got to give the care-givers a decent wage instead of this crappy minimum wage, you get what you pay for, don't you? And I thought it was very reasonable. But my Dad was very fortunate. He could afford it. Very fortunate. I mean, how, how can you put a cost on looking after, good quality care? (Mr Evan's daughter)

Nevertheless, cost was clearly a factor limiting hours of care. Most families reported starting with a modest amount of paid care - perhaps one hour a day for some days during the week - but tended to increase these if they could afford to do so, as the need for care intensified. Financial considerations prevented some respondents from increasing hours to a level that would have been preferred. Mrs Tomlinson's daughter observed that she had been cautious in the amount of care she put in place for her mother, valued as this was. If she had known the relatively short time her mother had to live she would have increased the care and been able to improve her quality of life:

If I'd known how long she, if somebody could have told me how long she was going to live, I'd have spent more ... to make life more pleasurable but I didn't know how long she was going to live. (Mrs Tomlinson's daughter)

Several participants expressed their awareness of DC as 'a business' and acknowledged the cost of care as necessary to generate profit as well as enable the HCWs to receive a reasonable rate of pay. Generally, however, respondents expressed little interest or awareness of the HCWs' terms and conditions of employment, rate of pay or the logistical challenges they encountered in the course of delivering care.

\section{Discussion}

The need for domiciliary care to support frail older people, including those with dementia, to live at home far outstrips the capacity of state provision, which is therefore targeted at those people with least economic support. In consequence, families are increasingly turning to the private sector (Institute of Public Care, 
2011; Alzheimer's Society, 2012; Baxter and Glendinning, 2014; Humphries et al., 2016; Wittenberg et al., 2018). The value of private home care is reflected in the willingness of families to pay high costs for a quality service; costs which inevitably restrict access to those who have the means at their disposal, and the hours of care that can be purchased. Nevertheless, as the amount of privately funded care is set to increase, it is important to understand informal care-givers' expectations and experience of the care they organise for relatives with dementia (Fraser et al., 2014; Manthorpe et al., 2016; Hengelaar et al., 2018). Different constructions of 'home care' and the comparison between state and privately funded provision enable an appraisal of how goals of service provision can realistically be formulated and delivered. The BOUGH study sought to explore the nature of 'good home care' through an investigation of a private-sector provider, which aimed to offer a flexible, responsive service to clients, based on a detailed assessment of needs, and a one-hour minimum time slot.

We found that family care-givers assumed responsibility for instigating paid home care for their relative, and prioritised companionship and provision of meals as the most important tasks, substituting the HCW's presence for their own, and enabling them to continue paid employment and protect their ongoing family and social life (Fraser et al., 2014). Participants rated the home care service highly. They stressed the reliability and punctuality of the HCWs as an important means of supporting the dignity and agency of their relative. Continuity of care was a prerequisite of good relationships with the person with dementia and their wider family. Participants reflected findings from other studies in placing greater emphasis on individual character, personality and relational skills as determinants of good care, rather than training (Walshe and Shutes, 2013; Fraser et al., 2014; Manthorpe et al., 2016). This is congruent with the current policy emphasis on values-based care, which seeks to attract staff with intrinsic characteristics and motivations in lieu of adequate investment in an infrastructure of care. This would incorporate an inclusive recruitment strategy supported by adequate pay and conditions, including workforce training and skill development (Manthorpe et al., 2016).

Promotional materials of private home care services explicitly orient themselves to families rather than individual clients directly receiving the service, and commit to providing 'family care' (Lolich, 2019). The study findings highlight the close involvement of certain relatives in home care, and the ambiguity of who is the 'client' in relation to home care services. Nominally this is the person being cared for, in the case of BOUGH, a person with dementia. Yet, in every case it was a family member who initiated, managed and organised payment of care. In some cases, it was, or had been, an adult child who assumed responsibility for managing care, despite the availability of a co-resident spouse who was the primary care-giver of the person with dementia. In several cases, it was evident that one or both of these individuals felt ambivalence, if not resistance, to accepting home care, and to suggestions that the amount of care should be increased (Pot et al., 2005; de Sao Jose et al., 2016). In general, however, it appeared that the persons with dementia accepted and appreciated the support of their adult children. Rather than acting, or wishing to be supported to act, as independent and selfdetermining agents, persons with dementia were embedded in a network of 
relational autonomy, in which family members played the major role in managing their care (Ho, 2008; Ribbens McCarthy, 2012; de Sao Jose et al., 2016; Smebye et al., 2016; Wittenberg et al., 2018). Thus, while respecting the preferences of clients, home care services should be family, rather than specifically client, centred (Sims-Gould and Martin-Matthews, 2008; Fraser et al., 2014; Hengelaar et al., 2018).

A further ambiguity concerns the relationships between HCWs and their clients. Within the domiciliary care sector, the delivery of excellent care is premised on good relationships, and the careful matching of client to care worker. It was evident that in some cases the HCWs provided not only very skilled care and companionship for the person with dementia, but also emotional and practical support for their relatives. This was sometimes described in quasi-kinship terms, despite being based on a commercial arrangement (Walshe and Shutes, 2013). The attribution of such 'fictive kinship' highlights the importance of the emotional as well as practical support, provided by HCWs, and of their role in a network of care extending beyond the immediate family (Sims-Gould and Martin-Matthews, 2008). However, family care-givers rarely expressed interest in the pay and conditions of the staff who provided such critical support and appeared to lack awareness of the logistical constraints they experienced in juggling family life with part-time, casual labour (Turner et al., 2018).

\section{Limitations}

Recruitment of research participants was problematic due to the gatekeeping role of the provider organisation and the slow and protracted process this involved due to the workload of management. Data collection was restricted to the pool of participants to which we had access, and this was effectively controlled by the managers of the home care provider organisation participating in the study. We were not able to obtain a clear picture of how many invitations had been issued, or the subsequent response rate. It is likely that managers made contact with relatives with whom they had a good relationship. Although participants were not wholly uncritical of the home care service they had experienced, it seems likely that clients who had a favourable view of the company were more likely to take part in the study. Nevertheless, the study includes a range of perspectives from family carers of relatives with varying severity of dementia and contributes to an understanding of how home care is understood and experienced in different domestic and economic settings.

\section{Conclusion}

High-quality home care is central to delivering the current policy priority to promote independence and autonomy among frail older people as a means of reducing the demands and costs of acute hospital and institutional care (Daly and Westwood, 2018). This policy involves shifting increasing responsibility and input for care to families, many of whom are, themselves, becoming increasingly old and frail. Little is known about the experience of family members assuming responsibility for care of older relatives affected by dementia, about their 
perspectives on the kind and quality of home care support they purchase, and the impact it has on their lives. The findings presented in this paper demonstrate the value of domiciliary care for family members in enabling them to continue functioning as families, workers and individuals with some quality of life (Pot et al., 2005). Home care thus encompasses much more than support for individual clients (Sims-Gould and Martin-Matthews, 2008).

In a fundamental sense, home care is about supporting relatives in their caring responsibilities as well as providing personal care for persons with dementia. In paying privately for care, relatives were able to realise their priorities in accessing continuity and reliability of service. They were provided with HCWs who could combine good interpersonal and communication skills with carrying out practical care. The provision of companionship for persons with dementia was prioritised over help with practical tasks and activities of daily living, although it is on these that local authority provision is largely focused (Koehler, 2017). Some relatives in the BOUGH study continued to provide a great deal of 'hands-on' care in supporting their relatives to live with dementia and assumed responsibility for management. The study highlights the importance of the relational, rather than the task-based, nature of good home care (Walshe and Shutes, 2013; Borgstrom and Walter, 2015).

Community support for increasing numbers of persons with dementia relies on unstinting commitment from family and friends. Some of these carers are older and frail, and therefore are themselves in great need of support to sustain their capacity and endurance and enable quality of life. Others are torn between caring for children or grandchildren and parents or grandparents: the 'sandwich generation'. Despite their pivotal importance in sustaining people with dementia in the community, family care-givers occupy an ambiguous status with very limited entitlement, or voice, in relation to formal services. These services appear to ignore the fundamental intertwining of interests involved in family groupings. This is a consequence of a system constrained by lack of time and resources (Humphries et al., 2016; UNISON, 2016). It is also an outcome of the importance given by the public sector to the individualisation of care, the promotion of personal autonomy and, also, to the protection of client confidentiality. Nevertheless, this paper points to the need to refocus domiciliary care as a collaborative and family, rather than an individually, oriented service, and to acknowledge the triadic relational nature of care, involving family carers as well as clients and care workers or health and social care professionals within care-giving networks (Sims-Gould and Martin-Matthews, 2008).

Author contributions. JS and KP devised the study and undertook the research interviews. KP carried out primary analysis of the data and drafted the manuscript. All authors contributed to analysis and interpretation of the data, reviewing and editing the text, and approved the final manuscript.

Financial support. The BOUGH ('Broadening Our Understanding of Good Homecare') study was funded by the National Institute for Health Research School for Social Care Research (NIHR SSCR; C088/T14-035). The views expressed in this paper are those of the authors and not necessarily those of the NIHR SSCR, National Health Service, the National Institute for Health Research or the Department of Health.

Conflict of interest. The authors declare no conflicts of interest. 
Ethical standards. The research received approval from the UK Health Research Authority Social Care Research Ethics Committee (reference number 15/IEC08/0043). Participants received information prior to agreeing to take part in the study and provided written consent to interviews.

\section{References}

Adelman R, Tmanova L, Delgado D, Dion S and Lachs M (2014) Caregiver burden: a clinical review. JAMA: The Journal of the American Medical Association 12, 1052-1062.

Age UK (2017) Briefing: Health and Care of Older People in England 2017. London: Age UK.

Alzheimer's Society (2012) My Life Until the End: Dying Well with Dementia. London: Alzheimer's Society.

Alzheimer's Society (2016) Fix Dementia Care: Homecare. London: Alzheimer's Society.

Aronson J (2002) Elderly people's accounts of home care rationing: missing voices in long-term care policy debates. Ageing \& Society 22, 399-418.

Baxter K and Glendinning C (2014) People Who Fund Their Own Social Care. London: National Institute for Health Research School for Social Care Research.

Bazeley P and Jackson K (2013) Qualitative Data Analysis with NVIVO. Los Angeles, CA: Sage.

Borgstrom E and Walter T (2015) Choice and compassion at the end of life: a critical analysis of recent English policy discourse. Social Science and Medicine 136, 99-105.

Braun V and Clarke V (2006) Using thematic analysis in psychology. Qualitative Research in Psychology 3, 77-101.

Bunn F, Goodman C, Pinkney E and Drennan VM (2016) Specialist nursing and community support for the carers of people with dementia living at home: an evidence synthesis. Health and Social Care in the Community 24, 48-67.

Burton M (2006) Grounding constructions of carers: exploring the experiences of carers through a grounded approach. International Journal of Social Work 38, 493-506.

Charmaz K (2006) Constructing Grounded Theory: A Practical Guide Through Qualitative Analysis. London: Sage.

Daly M and Westwood S (2018) Asset-based approaches, older people and social care: an analysis and critique. Ageing \& Society 38, 1087-1099.

de Sao Jose J, Barros R, Samitca S and Teixeira A (2016) Older persons' experiences and perspectives of receiving social care: a systematic review of the qualitative literature. Health and Social Care in the Community 24, 1-11.

Dyck I, Kontos P, Angus J and McKeever P (2005) The home as a site for long-term care: meanings and management of bodies and spaces. Health and Place 11, 173-185.

Fraser K, Archibald M and Nissen C (2014) Uncovering the meaning of home care using an arts-based and qualitative approach. Canadian Journal on Aging 33, 246-258.

Hengelaar A, van Hartingsveldt M, Wittenberg Y, van Etten-Jamaludin F, Kwekkeboom R and Satink T (2018) Exploring the collaboration between formal and informal care from the professional perspective. Health and Social Care in the Community 26, 474-485.

Ho A (2008) Relational autonomy or undue pressure? Family's role in medical decision-making. Scandinavian Journal of Caring Sciences 22, 128-135.

Humphries R, Thorlby R, Holder H, Hall P and Charles A (2016) Social Care for Older People: Home Truths. London: King's Fund.

Institute of Public Care (2011) People Who Pay for Care: Quantitative and Qualitative Analysis of Self-funders in the Social Care Market. London: Institute of Public Care.

Koehler I (2017) Paying for It: The Human Cost of Cut-price Care. London: Local Government Information Unit.

Lolich L (2019) The prioritisation of choice in eldercare: the case of Ireland. International Journal of Care and Caring 3, 1-14.

Manthorpe J, Harris J, Samsi K and Moriarty J (2016) Doing, being and becoming a valued care worker: user and family carer views. Ethics and Social Welfare 11, 79-91.

Milligan C, Turner M, Blake S, Brearley S, Seamark D, Thomas C, Wang X and Payne S (2016) Unpacking the impact of older adults' home death on family care-givers' experiences of home. Health and Place 38, 103-111. 
National Institute for Health and Care Excellence (2015) Costing Statement: Home Care. Implementing the NICE Guideline on Home Care: Delivering Personal Care and Practical Support to Older People Living in Their Own Homes (NG21). London: National Institute for Health and Care Excellence.

Ohwaki K, Hashimoto H, Sato M, Tamiya N and Yano EM (2009) Predictors of continuity in home care for the elderly under public long-term care insurance in Japan. Aging Clinical and Experiemental Research 21, 323-328.

Oliveira D, Vass C and Aubeeluck A (2017) Quality of life on the views of older family carers of people with dementia. Dementia 18, 990-1009.

Pot AM, Zarit SH, Twisk JWR and Townsend AL (2005) Transition in caregivers' use of paid home help: associations with stress appraisals and well-being. Psychology and Aging 20, 211-219.

Ribbens McCarthy J (2012) The powerful relational language of 'family': togetherness, belonging and personhood. Sociological Review 60, 68-90.

Schneider J, Kavanagh S, Knapp M, Beecham J and Netten A (1993) Elderly people with advanced cognitive impairment in England: resource use and costs. Ageing \& Society 13, 27-50.

Sims-Gould J and Martin-Matthews A (2008) Themes in family care-giving: implications for social work practice with older adults. British Journal of Social Work 38, 1572-1587.

Smebye KL, Kirkevold M and Engedal K (2016) Ethical dilemmas concerning autonomy when persons with dementia wish to live at home: a qualitative, hermeneutic study. BMC Health Services Research 16, 21.

Taylor BJ and Donnelly M (2006) Risks to home care workers: professional perspectives. Health, Risk and Society 8, 239-256.

Turner N, Schneider J, Pollock K, Travers C, Perry-Young L and Wilkinson S (2018) 'Going the extra mile' for older people with dementia: exploring the voluntary labour of homecare workers. Dementia, doi:10.1177/1471301218817616.

UNISON (2016) Suffering Alone at Home: A UNISON Report on the Lack of Time in Our Homecare System. London: UNISON.

Walshe K and Shutes I (2013) Care relationships, quality of care and migrant workers caring for older people. Ageing \& Society 33, 393-420.

Wiles J (2003) Informal caregivers' experiences of formal support in a changing context. Health and Social Care in the Community 11, 189-207.

Wittenberg Y, Kwekkeboom R, Staaks J, Verhoeff A and de Boer A (2018) Informal caregivers' views on the division of responsibilities between themselves and professionals: a scoping review. Health and Social Care in the Community 26, e460-e473. 